\title{
STUDYING THE ACTIVITY OF Chenopodium album SEED EXTRACTS AND Fusarium sambucinum CULTURE LIQUID AGAINST SEVERAL PLANT PATHOGENIC FUNGI
}

\author{
Yu.V. SEMINA ${ }^{1}$, L.A. SHCHERBAKOVA ${ }^{1}$, M.P. SLEZINA ${ }^{2}$, T.I. ODINTSOVA ${ }^{2}$
}

\begin{abstract}
${ }^{1}$ All-Russian Research Institute of Phytopathology, Federal Agency of Scientific Organizations, 5, Institute, pos. Bol'shie Vyazemy, Odintsovskii Region, Moscow Province, 143050 Russia, e-mail semina_yulia@yahoo.com, larisa@vniif.ru; ${ }^{2}$ N.I. Vavilov Institute of General Genetics RAS, Federal Agency of Scientific Organizations, 3, ul. Gubkina, Moscow, 119333 Russia, e-mail omey@list.ru, odintsova2005@rambler.ru
\end{abstract} Acknowledgements:

The authors thank T. Korostyleva for plant collecting.

Supported by Russian Scientific Foundation (project No. 16-16-00032)

Received June 16, 2016

\section{Abstract}

Plant extracts and microbial culture liquids contain a great number of bioactive substances, including potential biofungicides, which are effective against plant deseases. Screening of extracts and cultural filtrates for ability to suppress several pathogenic fungi that damage various agricultural plants can result in discovery of new compounds with a broad range of fungicidal activity. This work is the first report on in vitro testing the activity of plant extracts, which obtained by serial extractions of Chenopodium album seeds with hexane followed by ethyl acetate and then with ethanol, and also Fusarium sambucinum culture liquid filtrate (CLF), against six widespread fungi (Alternaria alternata, A. dauci, A. radicina, Bipolaris sorokiniana, Septoria tritici, Stagonospora nodorum) that are strongly pathogenic for several economically important crops. These fungi were found to demonstrate different sensitivity to CLF and seed extracts. Thus, CLFs with the activity level that was shown earlier for Stagonospora nodorum and A. radicina (effective dilutions up to 1:200 и 1:5, respectively) fully inhibited spore germination of all pathogens except $B$. sorokiniana, saving their antifugal activity to dilutions 1:5 (for $A$. dauci) or 1:50 (for Septoria tritici). Seed extracts possessed no toxicity against Stagonospora nodorum, Septoria tritici, A. dauci and A. radicina, but some of them reduced A. alternata and B. sorokiniana spore germination. For instance, after seed extraction with hexane followed by ethyl acetate, the number of germinated B. sorokiniana spores decreased by $66 \%$ as compared to control. Hyphae of spores germinated in diluted CLF were morphologically defective and much shorter than control ones. Besides, a significant growth retardation of Stagonospora nodorum, Septoria tritici and B. sorokiniana mycelia was observed on agar media supplemented with CLF $(100 \mu \mathrm{g} / \mathrm{ml})$. Collectively, these results suggest that further research of CFL and the seed extracts can result in identification of anifungal metabolites, which could be promising as biofungicides against leaf and glume blotches of wheat, spot blotch or common root rot of other cereals, and Alternaria diseases of carrot.

Keywords: Chenopodium album, Fusarium sambucinum, fungitoxicity, biofungicides, glume and leaf blotches, spot blotch, common root rot, Alternaria diseases

Plants and microorganisms produce many biologically active compounds, which functions are the subject of intense research. In particular, one of the modern trends in agricultural science is seeking for active ingredients to create biofungicides and other biopesticides [1-3] as an alternative or an adjunct to available chemical pesticides [4-8]. These promising compounds of microbial or plant origin include antimicrobial peptides and other secondary metabolites [911]. Their most accessible sources are extracts of wild (often weed) plants, as well as the culture liquid (CL) of fungi and bacteria grown in vitro [12-17].

Moreover, plant extracts and culture filtrates with pesticidal activity may be used to treat plants without additional (sometimes cost and complicated) purification [18-21]. For example, it was shown that the methanol extracts of lamb's quarters (Chenopodium album) inhibit accumulation of Macrophomina phaseolina fungus biomass in submerged culture [22], and a non-phytotoxic CL 
of the FS-94 isolate of Fusarium sambucinum Fuckel effectively inhibits in vitro germination of spores in causal agents of Stagonospora glume blotch and black rot of carrots $[16,17)$.

It is obvious that a particular interest for crop protection is in searching for extracts and filtrates, able to simultaneously suppress the development of several fungi pathogenic to various crops.

In view of this, we for the first time investigated the activity of the extracts of Chenopodium album seeds and CL filtrates of a non-pathogenic Fusarium sambucinum against six common plant pathogenic fungi (Alternaria alternata, A. dauci, A. radicina, Bipolaris sorokiniana, Septoria tritici, Stagonospora nodorum), which cause serious damage to many economically important crops.

Techniques. To prepare plant extracts, $30 \mathrm{~g}$ of lamb's quarters (C. album) seeds were powdered and extracted sequentially with hexane, ethyl acetate and ethanol (a ratio for each solvent 1:8 w/v) under vigorous stirring for $1 \mathrm{~h}$ at room temperature. After each extraction step, the homogenate was centrifuged at $10,000 \mathrm{~g}$ and at $4{ }^{\circ} \mathrm{C}$ for $10 \mathrm{~min}$, the supernatant was filtered through a paper filter and evaporated to dryness in a rotary evaporator. The precipitate was stored at $-80{ }^{\circ} \mathrm{C}$ and dissolved immediately prior to experiments in a minimal volume of $5 \%$ dimethyl sulfoxide (DMSO).

The culture liquid filtrate (CLF), obtained by submerged cultivation of the FS-94 isolate of $F$. sambucinum (16), was purified from culture medium components and low molecular weight exometabolites, not assimilated by the fungus, by means of ultrafiltration fractionation [23], while washing the CLF concentrate with sterile distilled water $\left(\mathrm{sdH}_{2} \mathrm{O}\right)$. Preparations of the concentrates transferred into aqueous medium were adjusted with $\mathrm{sdH}_{2} \mathrm{O}$ up to a volume of the initial CLF, sterilized by filtration through a $0.22 \mu \mathrm{m}$ membrane (GPWP type, MilliporeSigma, USA), frozen and stored until use at $-20{ }^{\circ} \mathrm{C}$.

Alternaria alternata (Fr.) Keissl; Bipolaris sorokiniana (Sacc.), Shoemaker; Septoria tritici Desm. and Stagonospora nodorum Berk., Castellani \& E.G. Germane isolates were obtained from the National Collection of Phytopathogenic Microorganisms in the All-Russian Research Institute of Phytopathology, and A. dauci (J.G. Kuhn), J.W. Groves \& Skolko and A. radicina Meier, Drechsler $\&$ Eddy isolates were from the Institute for Breeding Research on Horticultural Crops, Germany. To prepare suspensions, on the day of the experiment fungal spores, using $\mathrm{sdH}_{2} \mathrm{O}$, were washed off the surface of the colonies grown for 14 days on PDA at $25{ }^{\circ} \mathrm{C}$ (A. alternata, B. sorokiniana, Stagonospora nodorum, Septoria tritici) or on vegetable broth agar medium at $22-23{ }^{\circ} \mathrm{C}$ (A. dauci, A. radicina). Spores were separated from mycelial fragments by filtering through cotton and nylon filters, then pelleted by centrifugation at 3,000 g for $20 \mathrm{~min}$ and resuspended in a minimal volume of $\mathrm{sdH}_{2} \mathrm{O}$.

To evaluate the plant extracts and CLF for fungitoxicity, a method of spore germination in a thin layer of agar was used. To do this, equal volumes of the initial suspension and the test samples were mixed so that the density of a final suspension was $10^{4} / \mathrm{ml}$ for $A$. alternata, A. dauci, A. radicina and B. sorokiniana or $3 \times 10^{3} / \mathrm{ml}$ for Stagonospora nodorum and Septoria tritici. The suspensions were incubated at a constant slow stir for 25-30 minutes at room temperature and then applied onto slides coated with $1 \%$ aqueous agar $(200 \mu$ per slide, 3 slides per each test option), which were placed in a moist chamber. The spores were germinated in the dark at $22{ }^{\circ} \mathrm{C}$ for $16-18$ (A. dauci, A. radicina, Stagonospora nodorum, Septoria tritici) or 5-6 hours (A. alternata и B. sorokiniana). As a control we used spore suspension in $\mathrm{sdH}_{2} \mathrm{O}$ in the experiments with CLF, and in sterile $2.5 \%$ DMSO for the analysis of the C. album extracts. The effects in- 
duced by CLF and extracts on germination of plant pathogens were evaluated by microscope, scanning at least 600 spores in each treated option and the control. Germination frequency was expressed as a percentage relative to either a number of spores germinated in the control or a total number of spores, scanned in the control and in the experimental options.

To evaluate the effect of CLF on the radial growth of colonies of Stagonospora nodorum, Septoria tritici и B. sorokiniana, they were grown for 14-16 days in the dark at $25{ }^{\circ} \mathrm{C}$ on the PDA containing the filtrate $(100 \mu \mathrm{l}$ $\mathrm{CLF} / \mathrm{ml}$ culture medium). The mycelium fragments were used as the inoculum to be spiked to the center of Petri dishes $(9 \mathrm{~cm}$ in diameter). Control cultures were grown under the same conditions on media without the addition of CLF. As cultures grew, the diameter of the colonies ( 2 measurements per each colony in 2 different directions, 3 dishes per test option) was measured and the average diameter of the colonies for each of the pathogens was calculated.

Tests on the spore germination and the study of the growth trends in the plant pathogens were repeated at least 3 times. Statistical processing of the results was performed using Statistica 6.0 software (SoftStat Inc., USA). The significance of differences vs. control $(\mathrm{p} \leq 0.05)$ was determined using $t$-test for independent variables.

Results. As we have previously found that the CLF was capable of inhibiting the germination of Stagonospora nodorum and A. radicina spores [16, 17], in this study we used these plant pathogens as the reference test objects for monitoring the activity of the resulting filtrates when evaluating their fungitoxicity against Septoria tritici, A. dauci, A. alternata and B. sorokiniana. These species are causative agents of dangerous diseases of important agricultural crops, such as leaf and glume blotches of wheat (Septoria tritici), barley leaf spot and common root rots of the grasses ( $B$. sorokiniana), carrot leaf blight (A. dauci), dark mildew of wheat ears, as well as blackspots of a variety of other plants (A. alternata) [24-27].

1. Comparative fungicidal activity of the culture liquid filtrate (CLF) of Fusarium sambucinum against Septoria, Helminthosporium and Alternaria pathogens

\begin{tabular}{l|c|c}
\hline \multicolumn{1}{c|}{ Pathogen } & $\begin{array}{c}\text { Germination of spores in the } \\
\text { CLF, \% of control }\end{array}$ & The CLF titer \\
\hline $\begin{array}{l}\text { Stagonospora nodorum } \\
\text { Septoria tritici }\end{array}$ & 0 & $1: 200(\mathrm{p}=0.02)$ \\
Bipolaris sorokiniana & $08.3 \pm 1.3$ & $1: 50(\mathrm{p}=0.01)$ \\
Alternaria radicina & 0 & No dilution \\
A. alternata & $5.0 \pm 0.80$ & $1: 5(\mathrm{p}=0.03)$ \\
A. dauci & $2.0 \pm 0.04$ & $1: 5(\mathrm{p}=0.02)$ \\
N o t e. The table presents the average values for 600 spores per each test option and a standard error (mean \pm SE) \\
and the maximum CLF dilutions, with which there was still significant $(\mathrm{p}=0.05)$ inhibition of spore germination \\
vs. control.
\end{tabular}

The tests have shown that the CLF with a typical fungicidal activity against the reference test objects (the absence of germinated spores in undiluted filtrates and the expected titers of 1:200 and 1:5, respectively, for Stagonospora nodorum and $A$. radicina) had a similar activity against Septoria tritici, $A$. alternata and $A$. dauci, and the inhibitory action of the CLF against $S$. tritici was more effective, although this species was 4 times less sensitive than the other causative agent of septoria wheat, i.e. Stagonospora nodorum (Table 1). As in the case with $A$. radicina, a statistically significant inhibition of germination of $A$. alternata and $A$. dauci spores was observed up to 5-fold dilution of the CLF, and in the initial filtrates the germination was inhibited almost completely. The fungus $B$. sorokiniana appeared to be resistant to the effect of CLF. Note that all the investigated plant pathogens, including $B$. sorokiniana, 
hyphae of spores, which retained the ability to germinate after exposure to CLF, had morphological defects, particularly marked thickenings, and were significantly shorter than in control (Fig. 1 ).
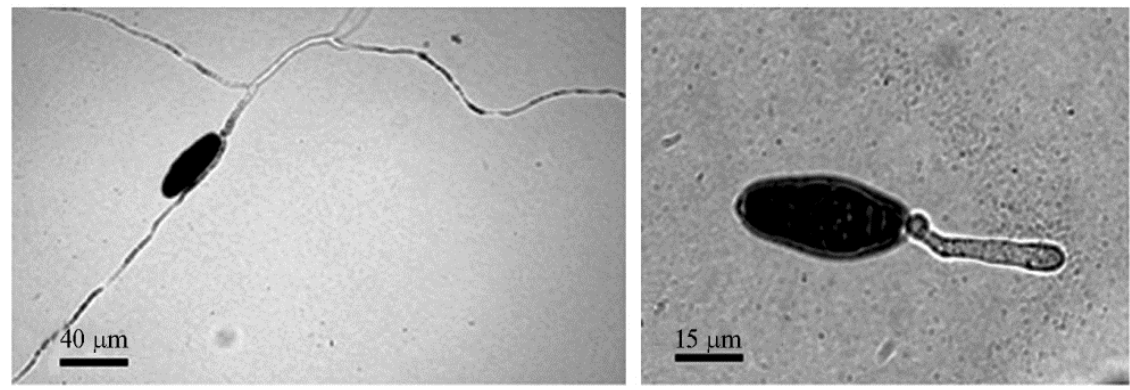

Fig. 1. Bipolaris sorokiniana spores, germinated in sterile distilled water (left) or in the culture liquid filtrate of Fusarium sambucinum (right).
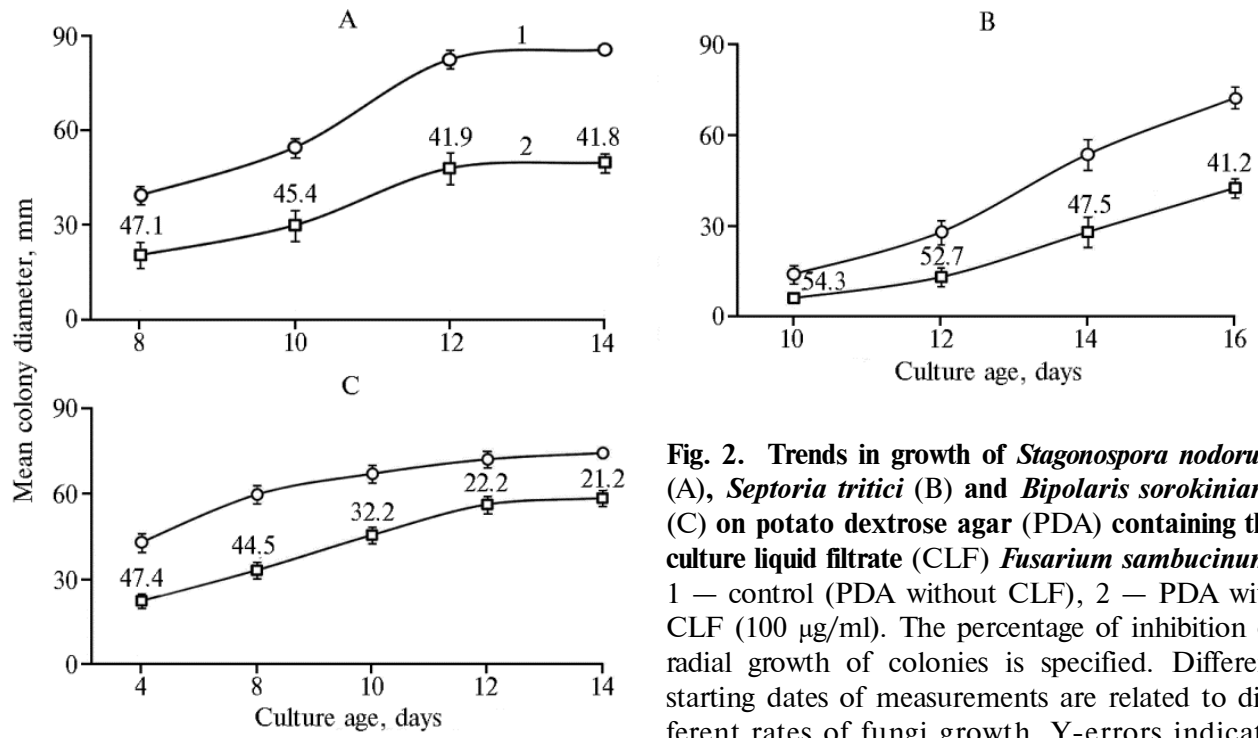

Fig. 2. Trends in growth of Stagonospora nodorum (A), Septoria tritici (B) and Bipolaris sorokiniana (C) on potato dextrose agar (PDA) containing the culture liquid filtrate (CLF) Fusarium sambucinum: 1 - control (PDA without CLF), 2 - PDA with CLF $(100 \mu \mathrm{g} / \mathrm{ml})$. The percentage of inhibition of radial growth of colonies is specified. Different starting dates of measurements are related to different rates of fungi growth. Y-errors indicate mean deviations for two experiments (6 replicates per test option per each experiment).

An analysis of the growth trends for the Stagonospora nodorum, Septoria tritici and B. sorokiniana mycelium in the presence of CLF revealed that, when cultured in media containing the filtrate, these plant pathogens markedly decreased their colony size (Fig. 2). The observed fungistatic effect on the growth of Stagonospora nodorum and Septoria tritici was stable and changed only slightly by the end of cultivation. In contrast, the inhibitory effect of the CLF on the growth of $B$. sorokiniana mycelium gradually weakened, however, the differences vs. control remained until the completion of observations (see Fig. 2).

Testing of preparations obtained by sequential extraction of $C$. album seeds using hexane, ethyl acetate and ethanol demonstrated that none of them possessed fungitoxicity against Stagonospora nodorum, Septoria tritici, A. dauci and $A$. radicina. Meanwhile, some of these plant extracts were able to inhibit to different extents the germination of the A. alternata and $B$. sorokiniana spores (Fig. 3). Thus, incubation of the A. alternata spores in the extracts obtained using hexane resulted in significant reduction in the number of germinated spores (by $16 \%$ ), and further decreased it in the ethanol-based extracts by $14 \%$ more.

The number of the $B$. sorokiniana spores, which germinated after incubation in extracts using hexane and ethyl acetate, was reduced by 34 and $32 \%$, respectively. Therefore, combined inhibition of germination using $C$. album ex- 
tracts for these plant pathogens reached $30 \%$ (A. alternata) and $66 \%$ (B. sorokiniana). Interestingly, that if $B$. sorokiniana concerned, the fungitoxicity effect, observed in two of the three experiments on the concurrent use of the CLF and preparations after extraction with hexane or ethyl acetate (Table 2), according to Limpel's formula $\left(\mathrm{E}_{0}<\mathrm{E}_{\text {real }}\right)$, had the synergistic action [28]. Furthermore, the estimated excess of the additive inhibitory effect in case of a combined use of the filtrate and both of the sequentially produced extracts amounted to 27-28\%.

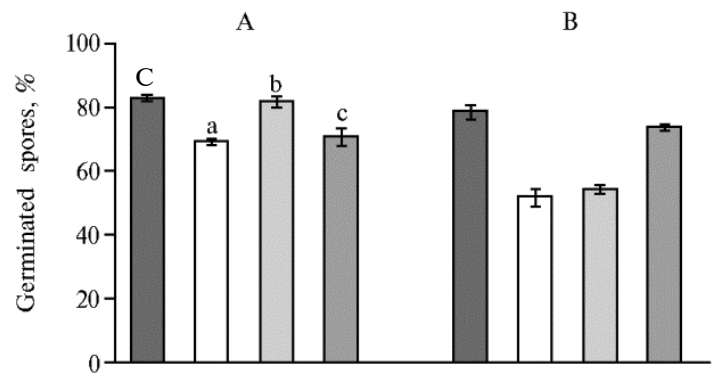

Fig. 3. Germination of the Alternaria alternata (A) and Bipolaris sorokiniana (B) spores when incubated with the preparations, obtained from the seeds of lamb's quarters (Chenopodium album) by sequential extraction with hexane (a), ethyl acetate (b) and ethanol (c). The extracts were dissolved in $2.5 \%$ dimethyl sulfoxide (DMSO); C control (2.5\% DMSO). The spores were placed in the studied extracts. To calculate the percentage of germinated spores (mean of 3 experiments), at least 600 spores per test option in each experiment were scanned

after 5-6 hours. Standard errors of mean are given.

2. Inhibition of spore germination (\% of total) in Bipolaris sorokiniana in a combined use of the Fusarium sambucinum culture liquid and Chenopodium album seed extracts

\begin{tabular}{c|c|c|c|c|c|c}
\hline \multirow{2}{*}{ CLF } & \multirow{2}{*}{ EH } & \multirow{2}{*}{ EEA } & \multicolumn{2}{|c|}{ CLF + EH } & \multicolumn{2}{c}{ CLF + EEA } \\
\cline { 4 - 7 } & & & $\mathrm{E}_{0}$ & $\mathrm{E}_{\text {real }}$ & $\mathrm{E}_{0}$ & $\mathrm{E}_{\text {real }}$ \\
\hline 0.8 & 36.3 & 31.9 & 37.1 & 49.6 & 32.7 & 47.2 \\
1.3 & 34.7 & 29.6 & 36.0 & 48.5 & 30.9 & 46.7 \\
0.6 & 31.0 & 34.2 & $31.4^{\mathrm{a}}$ & $31.9^{\mathrm{a}}$ & $34.8^{\mathrm{b}}$ & $35.2^{\mathrm{b}}$
\end{tabular}

N o t e. EH, EEA - extraction withhexane or ethyl acetate, respectively; titer of culture liquid filtrate (CLF) 1:2. $\mathrm{E}_{0}-$ expected additive effect, $\% ; \mathrm{E}_{0}=(\mathrm{X}+\mathrm{Y})-\mathrm{XY} / 100$, where $\mathrm{X}-\mathrm{CLF}, \mathrm{Y}-\mathrm{EH}$ or EEA. $\mathrm{E}_{\text {real }}-$ Effect (\%) obtained in the experiment. The differences between E0 vs. Ereal are significant at $p=0.05$, except for the values designated with the same Latin letters. If E0 < Ereal (28), the inhibitory effect is synergistic.

Thus, our results on evaluating the influence of the Fusarium sambucinum culture liquid and Chenopodium album seed extracts on in vitro development of six pathogenic fungi suggest a promising outlook of further research devoted to the composition of these products aimed at identifying the metabolites responsible for the antifungal activity, as well as to assume the possibility of creating biopesticides based on them against leaf and glume blotches of wheat, Alternaria diseases of carrots and spot blotch of the grasses.

\section{REFEREN C ES}

1. K a n d y b i n N.V. Zashchita rastenii, 1991, 1: 10-13 (in Russ.).

2. Cantre 11 C.L., D a y a n F.E., D u k e S.O. Natural products as sources for new pesticides. J. Nat. Prod., 2012, 75: 1231-1242 (doi: 10.1021/np300024u).

3. Gupta S., Dikshit A.K. Biopesticides: An ecofriendly approach for pest control. Journal of Biopesticides, 2010, 3: 186-188.

4. Mazid S., Rajkhow a R.C., Kalit a J.C. A review on the use of biopesticides in insect pest management. Int. J. Sci. Adv. Tech., 2011, 1: 169-178.

5. D a a y F., S ch mitt A., B e la nge r R.R. Evidence of phytoalexins in cucumber leaves infected with powdery mildew following treatment with leaf extracts of Reynoutria sachalinensis. Plant Physiol., 1997, 113: 719-727 (doi: 10.1104/pp.113.3.719).

6. He ga z i M.A., E 1-K o t G.A.N. Efficacy of some essential oils on controlling powdery mildew on zinnia (Zinnia elegans L.). Journal of Agricultural Science, 2010, 2: 63-74 (doi: $10.5539 /$ jas.v2n4p63).

7. Shcherbakova L.A. Some natural proteinaceous and polyketide compounds in plant protection and their potential in green consumerization. In: Natural products in plant pest management /N.K. Dubey (ed.). CABI International, 2011: 109-133.

8. Moharam M.H.A., Obiadalla Ali H.A.E. Preventative and curative effects of several 
plant derived agents against powdery mildew disease of okra. Not. Sci. Biol., 2012, 4: 76-82.

9. Varma J., Dube y N.K. Perspective of botanical and microbial products as pesticides of tomorrow. Cur. Sci. India, 1999, 76: 172-179.

10. Montesinos E. Antimicrobial peptides and plant disease control. FEMS Microbiol. Lett., 2007, 270: 1-11 (doi: 10.1111/j.1574-6968.2007.00683.x).

11. Shukla R., Kum ar A., Prasad C.S., Srivastava B., Dubey N.K. Antimycotic and antiaflatoxigenic potency of Adenocalymma alliaceum Miers. on fungi causing biodeterioration of food commodities and raw herbal drugs. Int. Biodeter. Biodegr., 2008, 62: 348-351 (doi: 10.1016/j.ibiod.2007.11.006).

12. Rivilla s-A c e ved o L.A., S o r i a $\mathrm{n}$ a $-\mathrm{G}$ a r c i a M. Isolation and biochemical characterization of an antifungal peptide from Amaranthus hypochondriacus seeds. J. Agr. Food Chem., 2007, 55: 10156-10161 (doi: 10.1021/jf072069x).

13. O nge na M., J a c ques P. Bacillus lipopeptides: versatile weapons for plant disease biocontrol. Trends Microbiol., 2008, 16(3): 115-125 (doi: 10.1016/j.tim.2007.12.009).

14. Odintsova T.I., Vassilevski A.A., Slavokhotova A.A., Musolyamov A.K., Finkina E.I., Khade eva N.V., Rogozhin E.A., Korostyleva T.V., Puk halsky V.A., Grishin E.V., Egorov T.A. A novel antifungal hevein-type peptide from Triticum kiharae seeds with a unique 10-cysteine motif. FEBS J., 2009, 276: 4266-4275 (doi: 10.1111/j.1742-4658.2009.07135.x).

15. Slavokhotova A.A., Odintsova T.I., Rogozhin E.A., Musolyamov A.K., Andreev Y.A., Grishin E.V., Eg o rov T.A. Isolation, molecular cloning and antimicrobial activity of novel defensins from common chickweed (Stellaria media L.) seeds. Biochimie, 2011, 93: 450-456 (doi: 10.1016/j.biochi.2010.10.019).

16. S e mi na Yu.V., S h che rbak ova L.A., D e v y at k i na G.A. Mikologiya i fitopatologiya, 2011, 45: 563-570 (in Russ.).

17. Semina Yu.V., Kremer R., Shcherbakova L.A., Klokke E., Notnage l' T. Vestnik zashchity rastenii, 2012, 2: 34-41 (in Russ.).

18. B o ck C.H., Shap i r o I la n D.I., We dge D.E., C a n t re 11 C.L. Identification of the antifungal compound, trans-cinnamic acid, produced by Photorhabdus luminescens, a potential biopesticide against pecan scab. J. Pest Sci., 2013, 87: 155-162 (doi: 10.1007/s10340-013-0519-5).

19. Duke S.O., Dayan F.R., Rom a ine J.G., Ri mando A.M. Natural products as sources of herbicides: current status and future trends. Weed Research, 2000, 40: 99-111 (doi: 10.1046/j.1365-3180.2000.00161.x).

20. Duke S.O., Baerson S.R., Cantrell C.L., Wedge D.E., Meepagala K.M., Pan Z., Ri m a ndo A.M., S chrader K., T ab a n c a N., Owe n s D.K., D a y n F.E. Phytochemicals for pest management: current advances and future opportunities. Recent Adv. Phytochem., 2013, 43: 71-94 (doi: 10.1007/978-3-319-00581-2-5).

21. Shcherbakova L., Semina Y., Nazarova T., Dorofeeva L., Dzhavakhiy a V., C a mp be 11 B. Potential for integrated control of the wheat pathogen, Stagonospora nodorum, by Folicur and extracellular compounds produced by isolate FS-94 of Fusarium sambucinum. IOBC-WPRS Bulletin, 2013, 89: 455-458.

22. J a v a id A., A min M. Antifungal activity of methanol and n-hexane extracts of three Chenopodium species against Macrophomina phaseolina. Nat. Prod. Res., 2009, 23(12): 1120-1127 (doi: 10.1080/14786410802617433).

23. S e mi n a Yu.V., S h c h e rbak ova L.A., D e v y a t k i na G.A. Vestnik Rossiiskoi akademii sel'skokhozyaistvennykh nauk, 2012, 3: 55-57 (in Russ.).

24. N a z a rova L.N. Zashchita i karantin rastenii, 2010, 3: 70-80 (in Russ.).

25. Kumar J., Schäfer P., Hückelhoven R., Langen G., Baltruschat H., S te i n E., N a ga raja n S., K o g e 1 K.-H. Bipolaris sorokiniana, a cereal pathogen of global concern: Cytological and molecular approaches towards better control. Mol. Plant Pathol., 2002, 3: 185-195 (doi: 10.1046/j.1364-3703.2002.00120.x).

26. Ty lo k o w k a K. Carrot seed-borne diseases caused by Alternaria species. In: Alternaria biology, plant diseases and metabolites. J. Chelkowski, A. Visconti (eds.). Elsevier Science Publishers, Amsterdam, 1992: 337-352.

27. Di ckins o n C.H. Leaf surface micro-organisms as pathogen antagonists and as minor pathogens, In: Strategies for control of cereal diseases. J.F. Jenkyn, R.T. Plumb (eds.). Blackwell Scientific Publications, Oxford, 1981: 101-121.

28. R i c h e r D.L. Synergism - a patent view. Pesticide Sci., 1987, 19: 309-315 (doi: 10.1002/ps.2780190408). 